\title{
A herpesvirus regulatory protein appears to act post-transcriptionally by affecting mRNA processing
}

\author{
Rozanne M. Sandri-Goldin ${ }^{1}$ and Grace E. Mendoza \\ Department of Microbiology and Molecular Genetics, College of Medicine, University of California, Irvine, \\ California 92717 USA
}

\begin{abstract}
Post-transcriptional control mechanisms play an important role in regulating gene expression for a number of viruses, especially in the regulation of late gene products. In this study we have investigated the mode of action of ICP27, an immediate-early regulatory protein of herpes simplex virus 1 (HSV-1) required for late gene expression. Transfection experiments have demonstrated that ICP27 can activate or repress expression depending on the target gene. Here, we show that the regulatory activity of ICP27 is independent of the target gene promoter sequences but, instead, depends on the presence of different mRNA processing signals. The activation function correlated with different polyadenylation sites, whereas the repressor function correlated with the presence of introns either $5^{\prime}$ or $3^{\prime}$ to the target gene-coding sequences. Poly $(\mathbf{A})^{+}$RNA levels were increased by ICP27 in transfections with a target gene having only an AATAAA recognition signal but no G/U box within the usual distance. In contrast, in the presence of ICP27, spliced target mRNAs were decreased 5- to 10-fold in transfections with target genes containing a $5^{\prime}$ or $3^{\prime}$ intron. These results suggest that this essential HSV-1 regulatory protein acts post-transcriptionally to affect mRNA processing and point to possible interactions between splicing and polyadenylation factors.
\end{abstract}

[Key Words: Herpesvirus post-transcriptional regulator; mRNA processing; gene expression]

Received August 30, 1991; revised version accepted February 21, 1992.

The regulation of gene expression in eukaryotic cells is controlled at several levels, including post-transcriptionally. The steady-state level of a specific mRNA can be regulated during processing, including polyadenylation and splicing (Leff et al. 1986), during transport from the nucleus to the cytoplasm (Cullen and Greene 1989), and by degradation of mature RNA in the cytoplasm Atwater et al. 1990). A number of DNA viruses and retroviruses use post-transcriptional mechanisms, particularly in the regulation of late gene expression during lytic growth. The adenovirus late transcription unit dominates at late times during infection producing up to $10 \%$ of total poly $\mid \mathrm{A})^{+} \mathrm{mRNA}$, which encodes the maiority of the viral structural proteins (Lucas and Ginsberg 1971; Shaw and Ziff 19801. Transcripts that arise from the major late promoter can be processed at any one of five possible poly(A) sites (Shaw and Ziff 1980; Nevins and Wilson 1981), as well as multiple splice acceptor sites (Berget et al. 1991; Nevins and Wilson 1981; Adami and Nevins 1988; Chow et al. 1991). Polyomavirus late nuclear transcripts are larger than genome in length and heterogeneous as a result of a decreased efficiency of termination that occurs at late times (Hyde-DeRuyscher

${ }^{1}$ Corresponding author. and Carmichael 1988). Processing into mature late viral mRNAs involves the splicing of noncoding leader exons to one another and to a coding exon (Barrett et al. 1991). In cytomegalovirus, a human herpesvirus, post-transcriptional events affect the regulation of all classes of viral genes (DeMarchi 1983; Goins and Stinski 1986; Geballe and Mocarski 1988; Stamminger et al. 1991); however, several late transcripts have been shown to differ from early transcripts by processing of the $3^{\prime}$ ends involving either alternate poly $(\mathrm{A})$ site cleavage or differential splicing of the late transcripts (Goins and Stinski 1986). Human immunodeficiency virus (HIV-1) also uses post-transcriptional controls for late gene expression. In this case, the viral product rev acts to induce the cytoplasmic accumulation of incompletely spliced HIV-1 mRNAs that encode the viral structural proteins by promoting the nucleocytoplasmic transport of these RNAs Chang and Sharp 1989; Emerman et al. 1989; Felber et al. 1989; Malim et al. 1989|. Adenovirus also encodes a polypeptide of the E1B gene that, by facilitating an intranuclear step in the metabolism of viral late mRNAs, results in their improved transport to the cytoplasm (Leppard and Shenk 1989). Another post-transcriptional mechanism, variation in mRNA stability, is used by human papillomavirus type 16 (HPV16) in regulating late 
gene expression (Kennedy et al. 1991). A negative regulatory element in the HPV16 genome located immediately upstream of the mRNA 3 '-processing signals acts as a late mRNA instability element (Kennedy et al. 1991).

We have been studying the mode of action of the human herpes simplex virus type 1 (HSV-1) immediateearly protein ICP27 (IE63) and its role in the switch from early to late expression during infection. ICP27 is a 63$\mathrm{kD}$ protein that localizes to the nucleus (Ackerman et al. 1984; Knipe and Smith 1986; Hardwicke et al. 19891, is phosphorylated (Wilcox et al. 1980), and is essential for viral replication (Sacks et al. 1985). Studies with ICP27 temperature-sensitive and null mutants have demonstrated that this protein is involved in the negative regulation of viral immediate-early and carly genes, and host cellular genes, and is required for the expression of HSV-1 late genes (Sacks et al. 1985; McCarthy et al. 1989; McMahan and Schaffer 1990; Rice and Knipe 1990). To assess directly the regulatory activities of ICP27 on HSV-1 target genes, we performed transfection experiments with the cloned ICP27 gene as an effector plasmid, and target plasmids consisting of HSV-1 promoter sequences fused to the chloramphenicol acetyltransferase (CAT) gene (Sekulovich et al. 1988). These experiments showed that ICP27 could repress or activate expression depending on the target plasmid in accord with its role during infection as a negative regulator of early expression and as an activator of late gene expression. Surprisingly, during these transfection studies, we found that ICP27 functions as a regulator in a promoterindependent manner. Specifically, target plasmids with identical promoter sequences but different reporter genes (CAT and lacZ) did not respond similarly to ICP27. This result prompted us to evaluate the differences in these reporter genes; and as described here, we found that dissimilar eukaryotic mRNA processing signals added to these reporter genes were responsible for the different effects seen with ICP27.

In this study we analyzed the ability of ICP27 to activate or repress expression of target genes having the same promoter sequences but with different polyadenylation regions or with the insertion of introns either 5 ' or $3^{\prime}$ to the reporter gene-coding sequences. Activation of target gene expression by ICP27 was found with some of the polyadenylation signals used, whereas no change in the level of expression was seen with others. In contrast, repression of expression was seen with ICP27 when an intron was present in the target gene regardless of which poly(A) region was used. A mutant containing an insertion within the activation region of ICP27 (Hardwicke et al. 1989/ was shown not to activate expression of those targets with specific poly(A) regions whose expression was increased by wild-type ICP27. Similarly, a mutant within the repressor region of ICP27 (Hardwicke et al. 1989 f failed to repress expression of targets with introns. Analysis of nuclear and cytoplasmic RNA showed that the level of spliced CAT mRNA was reduced in transfections with ICP27, but the distribution of spliced products was similar, which suggests that ICP27 is not in- volved in transport. Together, these results point to a post-transcriptional role for ICP27 at the level of mRNA processing.

\section{Results}

To assess the regulatory activities of ICP27, transfection experiments have been performed. In these studies, ICP27 was shown to have little or no effect on its own on target gene expression when HSV-1 early or late promoters were used in the target constructs. However, when ICP27 was added in combination with two other HSV-1 trans-activators, namely ICP4 and ICP0, either a repression of the activation seen with ICP4 and ICPO or an augmentation of that activation was seen depending on the target gene (Everett 1986; Block and Jordan 1988; Rice and Knipe 1988; Sekulovich et al. 1988; Hardwicke et al. 1989; Rice et al. 1989; McMahan and Schaffer 1990). Thus, ICP27 repressed ICP4- and ICP0-activated expression of pTK-CAT, which contains the early promoter from the thymidine kinase gene, whereas it enhanced the expression of pVP5-CAT, which contains the late promoter from the major virion capsid gene (Sekulovich et al. 1988; Hardwicke et al. 1989). For this reason, transfection experiments with ICP27 are performed routinely in the presence of ICP4 and/or ICPO. By constructing a set of in-frame insertion and deletion mutations (Hardwicke et al. 1989), we showed further that the activation region of ICP27 maps to the carboxy-terminal half of the protein, that activation mutations are transdominant to the wild-type protein (Smith et al. 1991), and that the repressor region maps to the carboxy-terminal 70-80 amino acids of ICP27 (Hardwicke et al. 1989). During the course of these studies, we constructed target plasmids containing HSV-1 promoters fused to a second reporter gene, namely the lac $Z$ gene encoding $\beta$-galactosidase, for the purpose of performing cotransfection experiments to determine whether ICP27 could activate expression of one target gene while repressing a second target within the same cell. In testing the $\operatorname{lac} Z$ targets, an unexpected result was found. As shown in Table 1 (columns 1 and 3), the ICP4- and ICP0-activated expression of pTK-CAT was repressed $\sim 12$-fold by adding ICP27 to the transfections, whereas ICP27 had no effect on the activated expression of pTK-LacZ. This result suggested that ICP27 was behaving as a reporter genedependent regulator because the TK promoter sequences were identical in both plasmids.

To analyze this promoter-independent effect of ICP27, we looked first at differences between the pTK-CAT and pTK-LacZ targets, besides protein-coding sequences. One striking difference was in the eukaryotic mRNA processing signals for expression in mammalian cells that had been added to the prokaryotic reporter genes. Thus, pTK-CAT (Sekulovich et al. 1988) derived from pSV2-CAT (Gorman et al. 1982) contained the small $\mathrm{t}$-antigen intron and early poly $(\mathrm{A})$ region from $\mathrm{SV} 40$, whereas pTK-LacZ, derived from pONl (Spaete and Mocarski 1985) contained only the SV40 early poly(A) signal but no intervening sequences. Furthermore, we discov- 
Table 1. Effects of ICP27 on the expression of different reporter genes containing the same promoter

\begin{tabular}{|c|c|c|c|c|c|c|c|}
\hline \multirow[b]{2}{*}{ Effectors } & \multicolumn{7}{|c|}{ Fold induction ${ }^{a}$} \\
\hline & pTK-CAT & pTK-CAT-SYN A & pTK-LacZ & $\mathrm{pTK}-\mathrm{CA}$ & LacZ & $\mathrm{pTK}-\mathrm{CT}-$ & $\mathrm{K}-\mathrm{LacZ}$ \\
\hline UN & 1 & 1 & 1 & 1 & 1 & 1 & 1 \\
\hline $\mathrm{ICP} 4+0$ & 24.2 & 1.7 & 8.1 & 33.5 & 5.8 & 1.5 & 6.9 \\
\hline $\mathrm{ICP} 4+0+27$ & 2.1 & 7.5 & 7.9 & 3.6 & 6.5 & 17.7 & 11 \\
\hline
\end{tabular}

The target plasmids pTK-CAT and pTK-CAT-SYN A, which contain the CAT reporter gene, and pTK-LacZ, which contains the lacZ reporter gene, were transfected into rabbit skin fibroblast $|R S F|$ cells either singly $(20 \mu \mathrm{g} / \mathrm{ml})$ or in combination with each other $(10$ $\mu \mathrm{g} / \mathrm{ml}$ for each target plasmid). The uninduced (UN' level of CAT activity or $\beta$-galactosidase activity found for each target plasmid in the absence of HSV-1 effectors was arbitrarily set at 1.0. Cotransfections with plasmids encoding the HSV-1 effectors ICP4 (pSG28K/B), ICPO (pRS-1) and ICP27 (pSG130B/S) added in equimolar amounts were performed as described previously (Sekulovich et al. 1988). ${ }^{a}$ The level of CAT activity or $\beta$-galactosidase activity obtained in the presence of effector plasmids was calculated relative to the uninduced level.

ered that the CAT cassettes in the pTK-CAT and pVP5CAT plasmids, which we had used as our model HSV-1 early and late target genes, were not the same. As described above, pTK-CAT was derived from pSV2-CAT; however, pVP5-CAT was derived from pSVOd ori $^{-}{ }_{-}$ CAT (Costa et al. 1985), a derivative of pUC-CAT described originally by Linney and Donerly (1983!. These investigators inserted a synthetic oligonucleotide linker $3^{\prime}$ to the CAT-coding sequences. This oligonucleotide contained the highly conserved polyadenylation recognition signal AATAAA (Proudfoot and Brownlee 1974); however, a second signal, termed the $\mathrm{G} / \mathrm{U}$ box $\mid \mathrm{Gil}$ and Proudfoot 1984; McDevitt et al. 1984; McLauchlan et al. 1985), which is also required for efficient polyadenylation, was not included. Therefore, it was necessary to determine whether ICP27 activated pVP5-CAT in response to the late promoter or because of different mRNA processing signals compared with pTK-CAT. Accordingly, the TK promoter and the VP5 promoter were fused to the CAT gene containing the SV40 small $t$ intron and early poly $(\mathrm{A})$ signals (termed CAT) and to the CAT gene containing only the poly(A) hexanucleotide AATAAA (termed CAT-SYN A). In addition, the promoter from the glycoprotein B (gB) gene (Bzik et al. 1984), another HSV-1 late gene, and the SV40 early promoter and enhancer (Gorman et al. 1982) were fused to each CAT gene so that it could be determined whether the promoter played any role in the ICP27 response.

Transfections with each target plasmid were performed, and CAT activity was measured. In each case, the uninduced level obtained from transfections with the target plasmid alone in the absence of effector plasmids was set at 1.0, and fold induction was calculated relative to this value. For all of the promoters used, opposite effects were obtained with ICP27, depending on the CAT construct (Fig. 1). For example, an almost 10fold reduction in the ICP4- and ICPO-activated response of pTK-CAT was seen with ICP27, whereas a 3-fold stimulation of that activation was seen for pTK-CATSYN A (Fig. 1). Similar results were seen for the CAT constructs with the gB, VP5, and SV40 promoters. When the CAT plasmid used contained the SV40 small $t$ intron and early poly(A) signals, repression of ICP4- and ICPOactivated expression was seen. On the other hand, aug- mentation of that activation was seen with the CATSYN A plasmids that lack the G/U box. It was also noted that ICP4- and ICPO-activated expression of the CATSYN A constructs under the control of HSV-1 promoters was significantly lower than that seen with the corresponding CAT plasmids (Fig. 1). These three promoters are generally induced to high levels by ICP4 and ICPO (Everett 1984; O'Hare and Hayward 1985; Blair and Wagner 1986; Gelman and Silverstein 1986). The low induction seen here is likely the result of inefficient polyadenylation of CAT transcripts, as would be predicted by the lack of a G/U box (Gil and Proudfoot 1984; McDevitt et al. 1984). This was illustrated further with the plasmids containing the SV40 early promoter and enhancer, which is a very strong promoter compared with the HSV-1 promoters tested. Although the data are presented here relatively, as fold induction, the actual level of CAT activity seen with pSV2-CAT was consistently 20- to 50 -fold higher than that found with pSV-SYN A. The level of expression obtained with these two plasmids was high enough to observe an effect by ICP27 on its own, without ICP4 or ICPO (Fig. 1). Thus, pSV2-CAT expression was reduced to $\sim 0.4$-fold by ICP27 alone, whereas pSV-CAT-SYN A expression was stimulated $\sim 5$-fold. This suggests that ICP27 does not interact with ICP4 and ICPO but that elevated expression of the targets, which is facilitated by these trans-activators, is required for the effects of ICP27 to be observed when weaker HSV-1 promoters are used. This was supported further in a related study on the effect of ICP27 on gene expression in a retroviral vector containing Moloney murine leukemia virus (MoMuLV) regulatory sequences, which again represents a strong promoter. ICP27 alone was shown to up-regulate expression (Chapman et al. 1992).

The previous result indicates that the activity of ICP27 on target gene expression is promoter independent. This was demonstrated further by the experiment shown in Table 1. In this experiment, the TK promoter was fused to the CAT plasmid derived from pSV2-CAT as described above, or to CAT-SYN A or LacZ. As stated earlier, neither an activation or repression of $\beta$-galactosidase activity was observed with ICP27 (Table 1, column 3), whereas pTK-CAT-activated expression was re- 


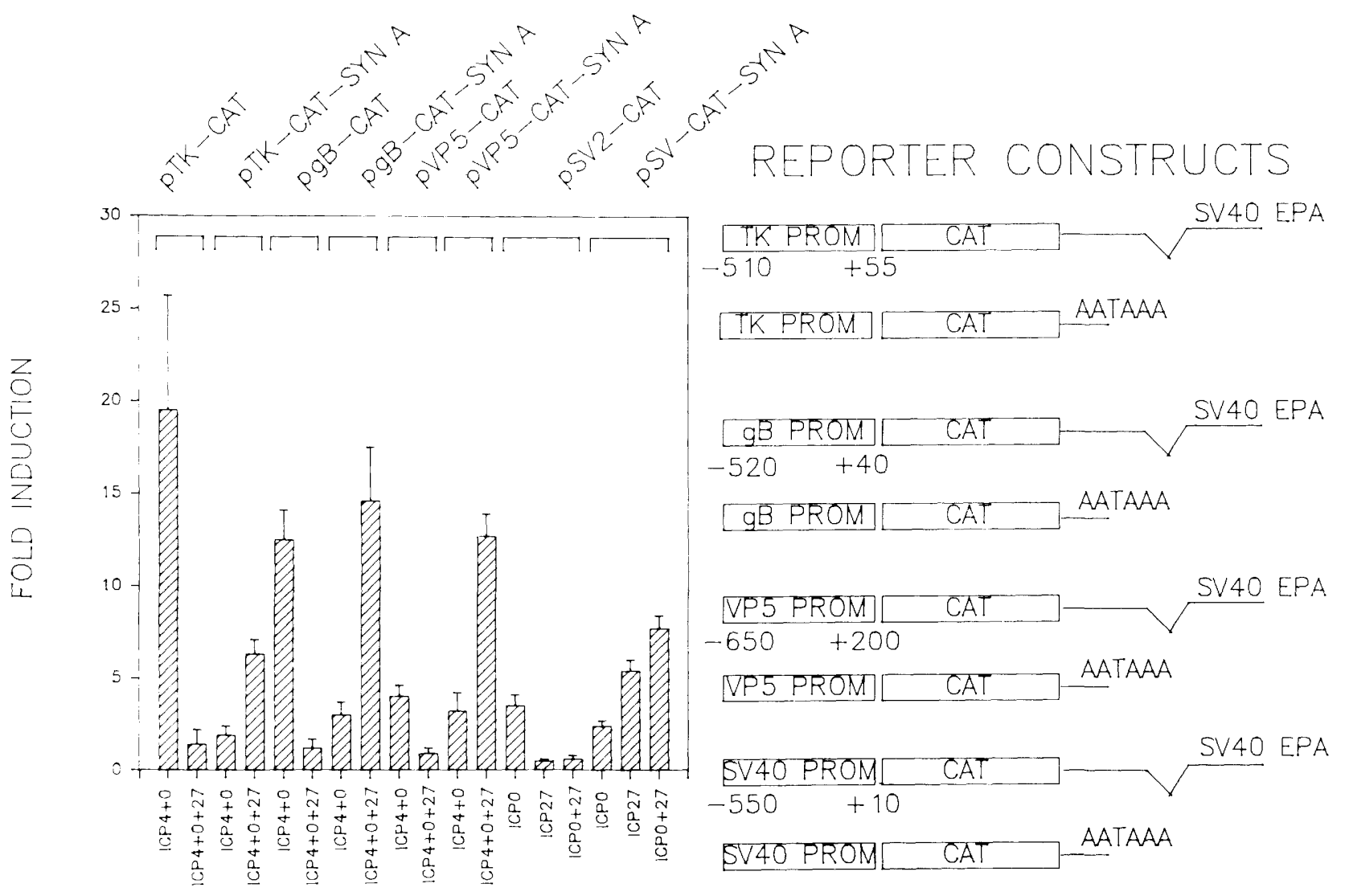

Figure 1. Effect of ICP27 on CAT expression from different CAT target plasmids. HSV-1 promoters from the thymidine kinase gene (TK; early), the glycoprotein B gene (gB; leaky late), and the major virion capsid gene (VP5; leaky late), as well as the heterologous SV40 early promoter and enhancer region, were fused to two different CAT reporter constructs. The plasmids labeled CAT were derived from pSV2-CAT (Gorman et al. 1982) and contain the SV40 small t-antigen intron and early polyadenylation region $3^{\prime}$ to the CAT-coding sequences as shown in the right panel. The constructs labeled CAT-SYN A were derived from pSV0d(ori ${ }^{-}$-CAT (Costa et al. 1985) and contain a synthetic oligonucleotide encoding the AATAAA poly(A) recognition site. Transfections were performed with target plasmids in the absence of effectors, and the values obtained were set at 1.0. Transfections with plasmids encoding the HSV-1 effectors ICP4 (pSG28K/B), ICP0 (pRS1), and ICP27 (pSG130B/S) were performed at equimolar concentrations of effector plasmids as described previously (Sekulovich et al. 1988). Results are presented as fold induction over the value obtained for the uninduced samples. Mean induction values are shown, and each transfection was performed at least six times to control for variability. The standard errors of the mean are shown as bars.

pressed (column 1). The expression of pTK-CAT-SYN A was activated further by ICP27, as was also seen with this plasmid in Figure 1. Even when targets that elicit a different response were cotransfected so that expression of different reporter genes could be measured, ICP27 affected expression of these targets as it does when they are transfected singly (Table 1). Thus, CAT expression was reduced 10 -fold by ICP27, whereas $\beta$-galactosidase activity was unaffected when pTK-CAT and pTK-LacZ were cotransfected even though both targets contained identical promoter sequences and were present together in the same cells. Similarly, CAT activity was stimulated $\sim 10$-fold from $p T K-C A T-S Y N A$, whereas $\beta$-galactosidase activity remained the same in the presence of ICP27. These results suggest strongly that ICP27 does not act at the transcriptional level, because its effects are promoter independent. They suggest further that ICP27 may have some involvement in mRNA processing or stabilization because plasmids with different processing signals responded differently.

The effect of ICP27 on target gene expression is dependent on different $m R N A$ processing signals

To examine the effect of ICP27 on gene expression in response to different mRNA processing sites in greater detail, a series of plasmids was constructed that differed only in processing signals. In all cases, HSV-1 TK promoter sequences from -510 to +55 (McKnight et al. 1981) were fused to CAT-coding sequences. The structure of each plasmid is shown in Figure 2. In the first five plasmids shown, different poly(A) regions were added $3^{\prime}$ to the CAT-coding sequences. The first plasmid, termed pTK-CAT-SYN A, was described earlier. The plasmid termed pTK-CAT-SV40 EPA contains the early polya- 


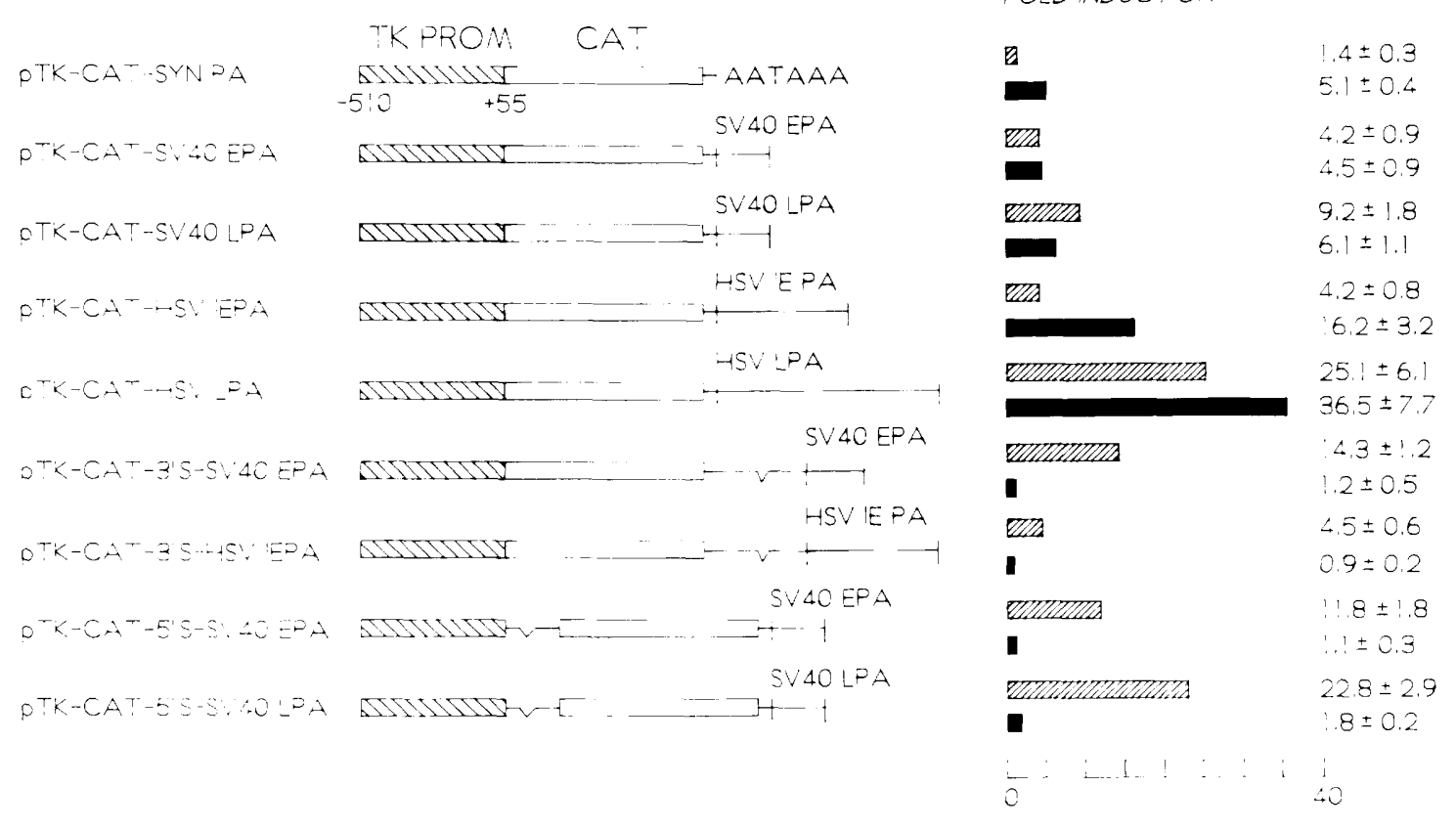

Figure 2. Effects of ICP27 on target gene expression depend on the presence of different mRNA processing signals. The target plasmids shown at left all contain the HSV-1 TK promoter from -510 to +55 and the CAT-gene coding sequences. The first five target plasmids contain different polyadenylation regions. pTK-CAT-SYN A was described in Fig. 1. The next four target plasmids contain the polyadenylation regions from the early region of SV40 ip TK-CAT-SV40-EPA), the late region of SV40 (pTK-CAT-SV40-LPA), the HSV-1 immediate-early ICP27 gene (pTK-CAT-HSV-IE PA), and the HSV-1 late glycoprotein C gene (pTK-CAT-HSV-LPA). The last four target plasmids contain introns, either the SV40 small $t$ intron positioned $3^{\prime}$ to the CAT gene (pTK-CAT-3'S-SV40-EPA and pTK-CAT-3'S-HSV-IE PA', or the SV40 late gene 16S/19S splice sites positioned in the 5'-leader region (pTK-CAT-5'S-SV40-EPA and pTK-CAT-5'S-SV40-LPAl, as well as the designatcd polyadenylation regions. Target plasmids were transfected with the HSV-1 effectors ICP4 (pSG28K/B), ICP0 (pRS1), and ICP27 (pSG130B/Si) as described previously (Sekulovich et al. 1988). The results are shown at right for each target plasmid and are presented as fold induction calculated relative to the value obtained with uninduced target plasmids, which was set at 1.0. (Hatched bar) $4+0$; (solid bar) $4+0+27$. Transfections were performed at least six times, and the standard errors of the mean are shown in parentheses.

denylation region from SV40, whereas PTK-CAT-SV40 LPA contains the SV40 late polyadenylation region. The plasmid pTK-CAT-HSV IE PA contains the 3 '-untranslated region and poly $|\mathrm{A}|$ sequences from the ICP27 gene itself, which is an HSV-1 immediate-early gene, whereas PTK-CAT-HSV LPA contains the untranslated region and poly(A) site from the HSV-1 late gene encoding glycoprotein C.

In transfections with these plasmids (Fig. 2), CAT expression was activated by ICP4 and ICPO at least fourfold above the uninduced level, except for pTK-CAT-SYN A, which was activated poorly as seen previously. When ICP27 was added to the transfections, a fourfold increase in CAT expression was found with pTK-CAT-SYN A and with pTK-CAT-HSV IE PA (Fig. 2). CAT expression was activated to high levels by ICP4 and ICPO in transfections with pTK-CAT-HSV LPA (25-fold), and a slight further activation was seen with ICP27. No change in the level of CAT expression by ICP27 was found when either the SV40 early poly(A) site or late poly|A) site was present. Table 1 showed a similar result for the plasmid pTK-LacZ, which differed from pTK-CAT-SV40-EPA only in the reporter gene-coding sequences. This indicates further that responses seen with ICP27 are related to RNA processing sites. In addition, because the targets used here differed only in the poly $(\mathrm{A})$ regions, these data suggest that ICP27 may affect poly(A) site utilization. It has been reported that HSV-1 induces a processing factor that stimulates poly(A) site usage (McLauchlan et al. 1989).

We then analyzed the basis of the repressor effect of ICP27, which had thus far only been found using a target plasmid that contained the small $t$ intron from SV40 positioned $3^{\prime}$ to the CAT gene. Huang and Gorman (1990) reported that this intron, when present in CAT expression vectors, could lead to aberrant splicing. That is, cryptic $5^{\prime}$ splice sites within the CAT-coding sequences were used sometimes, resulting in lower CAT expression compared with that seen in vectors lacking this intron. Although we had observed high levels of activation by ICP4 and ICP0 using CAT vectors derived from pSV2-CAT containing this intron (Fig. 1), it was necessary to determine whether the down-regulatory effect of ICP27 was related to the effects observed with this particular intron and its positioning. Therefore, we constructed three CAT plasmids with introns and compared these with the derivative of pSV2-CAT. In Figure 2 , the construct formerly referred to as pTK-CAT is 
called pTK-CAT-3'S-SV40 EPA to clarify the processing sites it contains and their positions. The plasmid designated as pTK-CAT-3'S-HSV IE PA was derived from the preceding plasmid, but the poly(A) region from ICP27 was substituted for the SV40 early poly(A) region. This was done to determine whether the poly $|\mathrm{A}|$ site made any difference in the level of expression in the presence of ICP27, because expression of pTK-CATHSV IE PA, which also contains this poly(A) site but no intron, was activated by ICP27. When the small $t$ intron was present however, ICP27 repressed the ICP4- and ICPO-activated expression of pTK-3'S-CAT-HSV IE PA (Fig. 2).

To determine whether ICP27 could repress expression from other intron-containing plasmids without potential complications of aberrant splicing, the plasmids pTKCAT-5'S-SV40-EPA and pTK-CAT-5'S-SV40 LPA were constructed. A fragment containing the SV40 19S late mRNA intron and a modified form of the SV40 16S late mRNA intron (Okayama and Berg 1983) was cloned into the 5'-leader region of pTK-CAT-SV40 EPA and pTK-CAT-SV40 LPA. CAT expression from both plasmids was activated efficiently by ICP4 and ICP0. CAT expression was reduced $>10$-fold when ICP27 was added. Therefore, the repressor effect of ICP27 appears to be related to the presence of introns rather than to a specific intron or to their positioning in target plasmids. In accord with this result, we found previously that ICP27 reduced ICPO mRNA lcvels (Sekulovich et al. 1988). The ICP0 gene contains two introns within its coding sequences (Perry et al. 1986). Therefore, ICP27 appcars to down-regulatc expression of spliced mRNAs.

\section{ICP27 affects the accumulation of CAT poly $(A)^{+}$ $m R N A$ in transfections with CAT expression plasmids containing different processing signals}

The results presented in Figure 2 demonstrated that the activation effect of ICP27 correlated with the presence of different poly(A) regions and the repressor effect correlated with the presence of splice sites or introns. It was therefore predicted that the level of poly $\{A\}^{+}$CAT RNA would be increased by ICP27 when transfections were performed with a CAT-SYN A-derived vector, whereas CAT mRNA levels would be decreased using a CAT vector containing an intron. To test this prediction, cells were transfected with the vectors pSV-CAT-SYN A or pSV2-CAT, either alone or with ICPO- and ICP27-expressing plasmids. Total RNA was isolated and poly $(\mathrm{A})^{+}$ RNA was selected by two successive purifications on oligo(dT)-cellulose columns. Poly $(A)^{+}$RNA was analyzed by ribonuclease protection assay (Fig. 3A). The structure of the CAT vectors used is shown in Figure 3B. Both target plasmids contained the SV40 early promoter and enhancer. This promoter was chosen to facilitate the RNA analysis because it is a stronger constitutive promoter than the HSV-1 promoters used elsewhere in this study. The $3^{\prime}$ sequence of pSV-CAT-SYN A is also shown in Figure 3B. The synthetic oligonucleotide (Linney and Donerly 1983) beginning with the AATAAA hexanucleotide is shown in uppercase letters. The adjoining vector region was sequenced and is shown in lowercase letters. The T- or GT-rich region, which has been termed the G/U box (Gil and Proudfoot 1984, McDevitt et al. 1984; McLauchlan et al. 1985) was not found in the usual position, 20-30 nucleotides downstream of the consensus hexanucleotide. However, a stretch of $\mathrm{Ts}$ can be found beginning $\sim 40$ nucleotides downstream from the AATAAA site.

The CAT antisense RNA probe that was used in the protection assays hybridized to a 250 -nucleotide region starting at the $5^{\prime}$ end of the CAT mRNA. This probe is described in the legend to Figure 4. In addition, a 205nucleotide protected fragment was also seen, which most likely resulted from "breathing" or local denaturation of the CAT RNA hybrids during the assay. An A/Trich stretch occurs within the CAT sequence. Cleavage in this region by RNase A would result in a protected fragment the size of the smaller fragment routinely observed.

The following observations were made in analyzing RNA levels in the experiment shown in Figure 3A, which support the hypothesis that ICP27 acts post-transcriptionally to affect RNA processing. First, as predicted by the results of the CAT assays, CAT mRNA levels were increased by ICP27 in transfections with pSVCAT-SYN A (Fig. 3A) but were decreased by ICP27 in transfections with pSV2-CAT (Fig. 3B), despite identical hetcrologous promoter sequences in both target plasmids. For example, in cotransfections with ICP27 and ICP0, CAT poly $(A)^{+}$mRNA levels were increased 10fold compared with the uninduced level and 5-fold compared with the ICP0-induced level for pSV-CAT-SYN A (Fig. 3A, lanes 1-3), whereas the amount of CAT poly $(\mathrm{A})^{+}$RNA seen in transfections with pSV2-CAT was decreased about fourfold when ICP27 was present compared with the level seen with ICPO alone. This was in contrast to the effects seen with ICPO, a promiscuous transcriptional activator (Everett and Dunlop 1984; Everett 1987; O'Hare and Hayward 1987), which elevated CAT mRNA levels in transfections with both pSVCAT-SYN A and pSV2-CAT (Fig. 3A). Second, the uninduced level of CAT poly $(\mathrm{A})^{+}$RNA detected in transfections with pSV-CAT-SYN A was $\sim 20$-fold lower than was found with pSV2-CAT, as would be expected if RNA transcribed from pSV-CAT-SYN A was not polyadenylated efficiently.

To investigate further the extent of polyadenylation of CAT RNA from transfections with pSV-CAT-SYN A, RNase protections were performed using a probe that spanned the $3^{\prime}$ end of the CAT mRNA. The 490-nucleotide antisense RNA probe used spanned a region from within the CAT-coding sequences that was 220 bases upstream of the AATAAA hexanucleotide to a site 200 bases downstream of the AATAAA in the pBR322 vector portion of pSV-CAT-SYN A . The RNA probe also contained an additional 20 bases between the $\mathrm{T} 7$ transcriptional start site and the inserted CAT fragment and 30 additional bases from the site of the insertion in the polylinker to the HindIII site used to linearize the plas- 
A

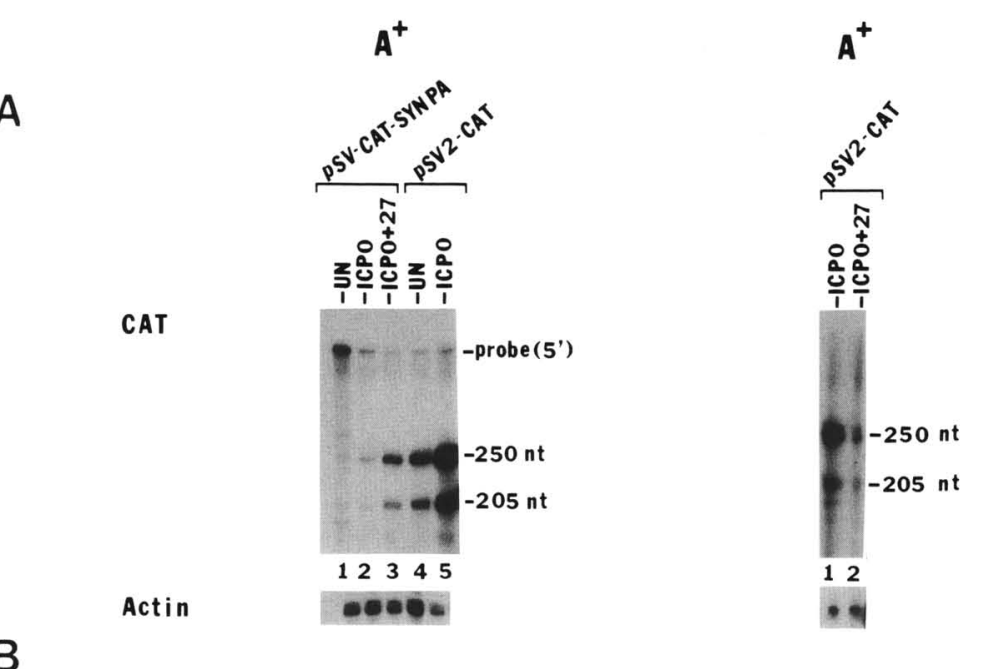

Figure 3. RNase protection analysis of polyadenylated RNA isolated from transfections with CAT vectors containing different processing sites. Total RNA was isolated from transfections with the target plasmids pSV-CAT-SYN A or pSV2CAT, whose structures are shown in $B$. Transfections were performed either with the target plasmid alone (UN) or in the presence of plasmids expressing ICP0, ICP27, or the ICP27 activator mutant S23. Poly A RNA was selected by oligoldT/-cellulose. RNase protections shown in $A$ were performed with a ${ }^{32} \mathrm{P}$-labeled antisense probe from the $5^{\prime}$ region of the CAT gene. The probe and the expected 250-nucleotide CAT protected frag. ment are shown in Fig. 4B. Protections shown in $C$ were performed with an antisense probe spanning the $3^{\prime}$ region of the CAT mRNA. The probe and the expected poly $\mid A)^{-}$protection product are described in the text. To ensure that equal amounts of RNA were recovered and processed from each transfection, one-tenth of the RNA from each sample was hybridized with a probe specific for $\beta$-actin. The size of the actin protected product is 250 nucleotides. Size markers (shown in $C$ ) were obtained by end-labeling HinfI-digested pBR322 DNA. The 3' RNA probe is also shown in C. Appropriate exposures of the autoradiographs were scanned by a laser densitometer to quantify the amount of CAT mRNA in each lane.

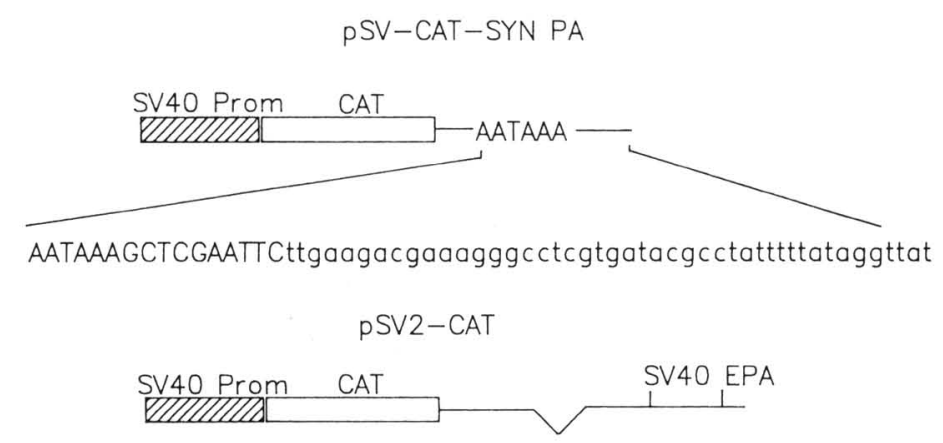

C

mid before transcription. Therefore, the RNA probe contained 50 bases of sequence that are not present in pSVCAT-SYN A so that any undigested probe (490 bases) could be distinguished from CAT RNA that extended the length of the probe (440 bases).

Transfections were performed with pSV-CAT-SYN A; however, ICPO was not added to the transfections. This was done to analyze the effect of ICP27 on polyadenylation directly without other trans-activators present because the CAT assay results in Figure 1 showed that activation could be seen with ICP27 alone. In addition, transfections were performed with an activator mutant of ICP27. The S23 mutant contains a 2-amino-acid insertion within the ICP27 activation region /Hardwicke et al. 1989), as seen in Figure 5. Analysis of total RNA showed a predominant protected fragment of 440 nucleotides for the uninduced sample, as well as for RNA from transfections with ICP27 and mutant S23 (Fig. 3C, left). This indicates that the CAT RNA extended at least 200 bases past the AATAAA hexanucleotide. A second band of 240 nucleotides was also seen in the ICP27-induced sample (Fig. 3C, lane 2). The expected size of protected CAT poly $(\mathrm{A})^{+}$RNA is $\sim 240$ bases if cleavage and poly(A) addition occurred within 10-30 bases down- 
A

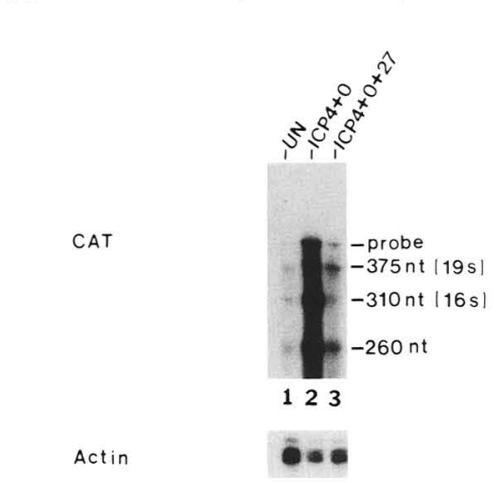

B

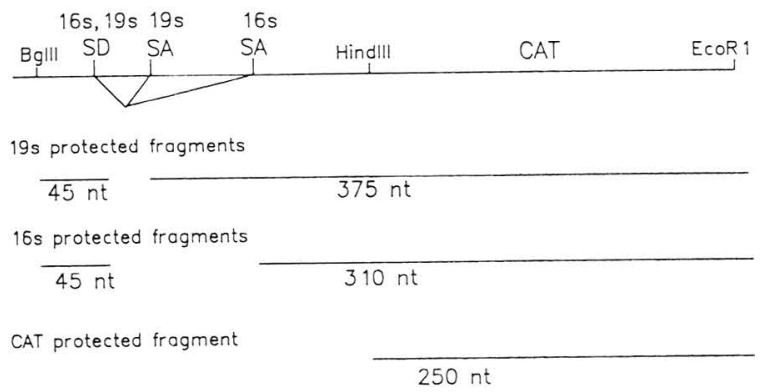

P TK. CAT · 5'S. SV LPA

C

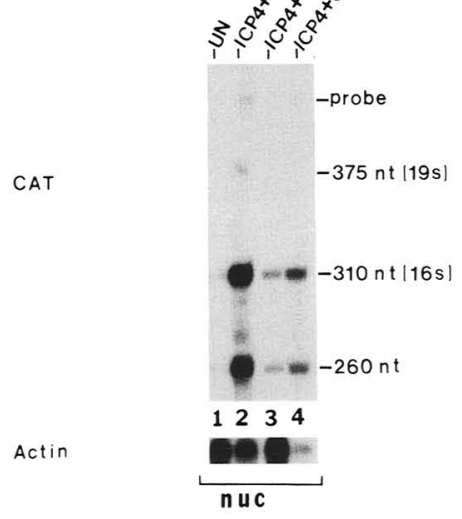

PTK.CAT·3'S SV EPA

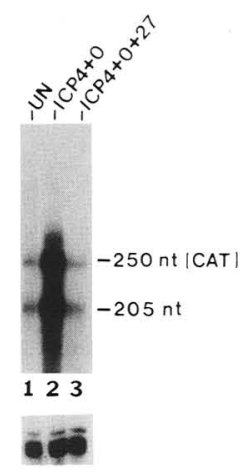

Figure 4. RNase protection analysis of spliced CAT mRNAs in the presence or absence of ICP27. (A) Total RNA was isolated from transfections with the target plasmids pTK-CAT-5'S-SV40 LPA or PTK-CAT-3'S SV40 EPA either uninduced (UN) or in the presence of plasmids expressing ICP4, ICPO, and ICP27. RNase protection analysis was performed using a ${ }^{32} \mathrm{P}$-labeled CAT antisense RNA probe shown in $B$. In the analysis of RNA from transfections with pTK-CAT5'S-SV40 LPA, a 375-nucleotide protected fragment was expected if the $19 \mathrm{~S}$ splice acceptor was used, and a 310-nucleotide product was expected if the $16 \mathrm{~S}$ splice acceptor was used. For RNA from transfections with pTKCAT-3'S-SV40 EPA, a 250-nucleotide protected fragment was expected from the HindIII site at the start of the CAT mRNA to the EcoRI site within the CAT gene. In $C$, nuclear and cytoplasmic RNA fractions were isolated as described in Materials and methods from transfections with pTK-CAT -5 'SSV40 LPA, either uninduced or with plasmids expressing ICP4, ICPO, ICP27, or the ICP27 repressor mutant N2. Each fraction was hybridized with the CAT probe shown in $B_{f}$ and the protected products were analyzed on denaturing polyacrylamide-urea gels. An aliquot of each RNA sample from $A$ and $C$ was hybridized with a probe specific for $\beta$-actin to determine whether equal amounts of RNA were recovered and processed for each sample. Approximately one-eighth as much RNA was recovered in the nuclear fraction from the transfection with $\mathrm{N} 2$ as seen in $C$ (lane 4). DNA size markers were obtained by endlabeling pBR322 DNA that had been digested with Hinfl. Appropriate exposures of the autoradiographs were scanned with a laser densitometer to quantify the amount of protected product in each lane. stream of the AATAAA site. This suggests that the 240nucleotide band represented poly $(\mathrm{A})^{+}$RNA. The $240-$ nucleotide product was about one-third as abundant as the larger, full-length product in the sample with ICP27, as determined by densitometer scanning. The 240-base product could barely be detected in the uninduced sample (lane 1) and in the S23 sample (lane 3), being present in nearly 20 -fold lower amounts than the 440 -base product. To confirm that the 240-nucleotide product represented poly $(\mathrm{A})^{+} \mathrm{RNA}$, a parallel sample to that shown in lane 2, where ICP27 was present, was fractionated on an oligo(dT)-cellulose column to enrich for poly $(\mathrm{A})^{+}$RNA. The material that bound to the column was designated as poly $(\mathrm{A})^{+}$, even though it was still contaminated with poly $(A)^{-}$RNA after just one fractionation. Material that flowed through the column was designated poly $(\mathrm{A})^{-}$. The 240-nucleotide product was found only in the poly $(\mathrm{A})^{+}$fraction. In addition, the ratio of the 440 -nucleotide product compared with the 240 -nucleotide product was $\sim 1.5: 1$, compared with $3: 1$ for total RNA. Also, twice as much of the 440-nucleotide product was found in the poly $(A)^{-}$fraction. These results indicate that the 440-nucleotide product represented unprocessed RNA. This was suggested further by Northern blot analysis of CAT total RNA from transfections with pSVCAT-SYN A either uninduced or induced with ICP27. A 
FOLD INDUCTION

EFFECTOR PLASMIDS

\begin{tabular}{|c|c|c|c|c|c|c|c|c|}
\hline \multirow[b]{2}{*}{ REPORTER CONSTRUCTS } & & \\
\hline & $1 \mathrm{CP} 4+0$ & $1 \mathrm{CP} 4+0+27$ & $\mid \mathrm{ICP} 4+0+\mathrm{S} 23$ & $\mathrm{ICP} 4+0+\mathrm{N} 2$ & WT HSV-1 & 27-LacZ & 27-LacZ/S23 & 27-LacZ/N2 \\
\hline DTK-CAT-SYN PA & $1.7(0.3)$ & $3.8(1.3)$ & $1.1(0.5)$ & $1.3(0.2)$ & $3.4(1.2)$ & $1.1(0.5)$ & $1.3(0.3)$ & $1.2(0.5)$ \\
\hline DTK-CAT-SV 40 EPA & $4.7(0.7)$ & $4.1(0.9)$ & $1.1(0.1)$ & $5.4(0.8)$ & $3.3(0.6)$ & $4.5(1.3)$ & $0.9(0.3)$ & $3.8(0.4)$ \\
\hline DTK-CAT-5'S-SV4O EPA & $6.2(2.1)$ & $1.2(0.2)$ & $1.2(0.3)$ & $5.9(0.7)$ & $3.2(0.9)$ & $16.5(2.4)$ & $1.8(0.8)$ & $15.3(1.9)$ \\
\hline DTK-CAT-3'S-SV4O EPA & $13.9(1.2)$ & $1.8(0.1)$ & 1.310 .51 & $13.7(0.7)$ & $0.9(0.3)$ & $13.9(1.6)$ & $1.4(0.5)$ & $12.6(1.0)$ \\
\hline DTK-CAT-SV $4 O$ LPA & $23.3(4.8)$ & $14.7(1.6)$ & $2.2(0.8)$ & $19.4(3.6)$ & $5.6(1.2)$ & $10.510 .9)$ & $1.9(0.4)$ & $8.2(0.7)$ \\
\hline DTK-CAT-5'S-SV4O LPA & $27 \mid\{5.1\}$ & $3.0(0.6)$ & $2.0(0.4)$ & $28.6(5.1)$ & 2.210 .51 & $11.9(0.9)$ & $3.4(0.5)$ & $10.1(1.1)$ \\
\hline DTK-CAT-HSV IEPA & $4.7(0.9)$ & $20.9\{3.5\rangle$ & 1.910 .51 & $6.9(0.7)$ & $25.1(1.9)$ & $12.4(1.2)$ & $2.7(0.8)$ & $10.3\langle 0.9\}$ \\
\hline DTK-CAT-3'S-HSV IEPA & $6.0(0.7)$ & $0.6(0.1)$ & $0.7(0.1)$ & $5.6(0.4)$ & $1.9(0.4)$ & $7.9(1.2)$ & $1.6(0.3)$ & $6.5(0.9)$ \\
\hline & Bom & & & S & & & & \\
\hline
\end{tabular}

\begin{tabular}{|c|c|c|}
\hline Mutonts & $\begin{array}{l}1 \\
\underset{\sim}{W}\end{array}$ & $z$ \\
\hline
\end{tabular}

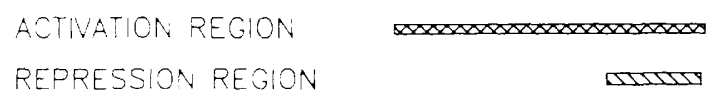

Figure 5. Effect of insertion mutations in the ICP27 gene on the expression of target plasmids with different mRNA processing sites Transfections were performed with the target plasmids shown, whose structures were described in Fig. 2. In the first four columns, plasmids expressing ICP4, ICP0, ICP27, or ICP27 insertion mutants were cotransfected with the target plasmids as indicated. In the last four columns, no effector plasmids were added to the transfections. Instead, RSF cells or cell lines expressing S23 or N2 were transfected with target plasmids and infected $16 \mathrm{hr}$ later with wild-type HSV-1 KOS or the ICP27 null mutant 27-LacZ /Smith et al. 1992!. Values are presented as fold induction relative to the value obtained with each uninduced target plasmid. Transfections were performed at least six times, and mean values are given. The standard errors of the mean are shown in parentheses. The positions of the insertion mutations within the ICP27-coding region are shown schematically along with the locations of the regions involved in activation and repression as defined by Hardwicke et al. 11989\}.

large heterogeneous band of $\sim 3.5-4 \mathrm{~kb}$ (the size of the target plasmid) was seen to hybridize with the CAT probe. A less abundant band of $\sim 900$ nucleotides ithe expected size of CAT poly $(A)^{-}$RNA] was seen only in the sample where ICP27 was present (data not shown).

Together, these results indicate that polyadenylation and cleavage of CAT RNA transcribed from pSV-CATSYN A is highly inefficient, resulting in long heterogeneous RNAs. ICP27 increased the efficiency of processing of the CAT RNA resulting in higher levels of poly $\mid \mathrm{A})^{+}$RNA.

ICP27 causes a reduction in the accumulation of spliced CAT mRNA

The results presented in Figure $3 \mathrm{~B}$ showed that CAT poly $(\mathrm{A})^{+}$mRNA levels were reduced when ICP27 was present in transfections with pSV2-CAT that contains the small t intron. Previously, we reported a similar result using Northern blot hybridization analysis. In that study, CAT mRNA levels were reduced nearly fourfold in transfections with pSV2-CAT and ICP27 alone compared with the uninduced level (Sekulovich et al. 1988). We also showed that ICP27 decreased the ICP4- and ICPO-activated level of CAT mRNA for vectors derived from pSV2-CAT but containing HSV-1 promoters in place of the SV40 promoter (Sekulovich et al. 1988). No decrease was seen with an ICP27 plasmid that contained an in-frame stop codon near the amino-terminal end of the protein, verifying that ICP27 was responsible for the effects observed (Sekulovich et al. 1988). However, these experiments did not address the question of whether CAT transcripts were spliced correctly when ICP27 was present or whether the reduced amount of CAT mRNA 
was similar in the nucleus and the cytoplasm. To address these points, transfections werc performed with the plasmid pTK-5'-CAT-SV40 LPA, and RNA was isolated and analyzed by ribonuclease protection analysis. This plasmid was chosen because it contains the SV40 16S/19S splice sites placed $5^{\prime}$ to the CAT-coding sequences rather than the SV40 small $t$ intron $3^{\prime}$ to the CAT gene, for which incorrect splicing patterns have been described (Huang and Gorman 1990). Control transfections were also performed with pTK-CAT-3'-SV40 EPA that contains the small $t$ intron $3^{\prime}$ to the CAT gene to directly compare the reduction in CAT mRNA accumulation.

The ${ }^{32}$ P-labeled antisense RNA probe used in the protection assays is shown in Figure 4B. This 480-nucleotide RNA probe was transcribed in vitro from a pGEMl-derived vector (see Materials and methods). It initiates within the CAT-coding sequences, spans the 16S/19S splice sequences, and terminates 10 bases past the BgIII site, which is at position +55 in the TK regulatory scquences. The expected protected fragments include a 375-nucleotide fragment if splicing occurs at the $19 \mathrm{~S} \mathrm{ac}-$ ceptor site, a 310-nucleotide fragment if splicing occurs at the $16 \mathrm{~S}$ acceptor site, and a 45-nucleotide fragment from the untranslated leader region of TK to the splice donor site. This latter fragment was run off of the gels. In addition, we routinely observed a 260-nucleotide fragment that would result from the $16 \mathrm{~S}$ spliced product if breathing occurred during the protection assays at the A/T-rich run within the CAT gene as was also observed in Figure 3. In protection assays using RNA from transfections with pTK-CAT-3'-SV40 EPA, a 250-nucleotide protected product was expected, as this vector does not contain the region between the BgIII and the HindIII sites. This product is labeled CAT-protected fragment in Figure 4B. Again, as in Figure 3, a smaller fragment of 205 nucleotides was seen that likely results from breathing at the A/T-rich stretch in the CAT gene. In more recent experiments, the temperature of the RNase treatment has been reduced to $4^{\circ} \mathrm{C}$, which results in a decrease in the amount of the smaller fragment, although it does not eliminate it (data not shown).

The overall amount of CAT RNA was reduced about sixfold in transfections with pTK-5'S-CAT-SV40 LPA and about ninefold for pTK-CAT-3'S-SV40 EPA in the presence of ICP27 compared with the level seen with ICP4 and ICP0 (Fig. 4A). These results are similar to what was found with pSV2-CAT (Fig. 3) and are in the range of the decrease in CAT activity found in transfections with these plasmids (Figs. 1 and 2). Therefore, the down-regulation of CAT RNA levels by ICP27 is not dependent on a specific intron or on the positioning of the intron. Furthermore, both the 19S spliced product and the $16 \mathrm{~S}$ spliced product were found in transfections with pTK-5'S-CAT-SV40 LPA in the presence of ICP27, but their amounts were reduced relative to the level seen with ICP4 and ICPO (Fig. 4A). In the latter case, splicing occurred about five times more frequently at the $16 \mathrm{~S}$ acceptor site compared with the 19S sitc (Fig. 4A, lane 2). This result is in accord with that reported by Okayama and Berg (1983), who constructed this modified intron and who found a similar ratio of $16 \mathrm{~S}$ to $19 \mathrm{~S}$ product. It can be concluded, therefore, that correctly spliced CAT mRNAs were produced in transfections with ICP27 but that their amounts were reduced.

It was also possible that ICP27 functioned at the level of mRNA transport similar to the HIV-1 $\mathrm{rev}$ protein (Chang and Sharp 1989; Emerman et al. 1989; Felber et al. 1989; Malim et al. 1989|. If that were the case, then a difference in the distribution of spliced versus unspliced RNA between the nucleus and the cytoplasm would be expected. Until now, we had analyzed total RNA from transfected cells. Therefore, nuclear and cytoplasmic RNA fractions were prepared from transfections with pTK-5'S-CAT-SV40 LPA. We also included a transfection with the ICP27 repressor mutant N2 in this experiment. The N2 insertion mutation occurs within the repressor region of ICP27 (Hardwicke et al. 1989) as shown in Figure 5. As shown in Figure 4C, the distribution of the 16S and 19S spliced products was similar in the nuclear and cytoplasmic RNA fractions in all cases. Unspliced RNA could not be detected in the nuclear fraction from the transfection with ICP27 (lane 3), indicating that unspliced RNA did not accumulate but was degraded rapidly. The amount of spliced CAT RNA seen in transfections with ICP27 was about scvenfold lower than the amount seen with ICP4 and ICPO (lane 2) in the nuclear fraction and sixfold lower in the cytoplasmic fraction. This result implies that ICP27 is not involved in facilitating RNA transport but exerts its effects on RNA levels in the nucleus. Consistent with the repressor mutant phenotype, as defined in CAT expression assays (Hardwicke et al. 1989), N2 did not lower the accumulation of spliced CAT RNA. The amount of spliced RNA detected in the nuclear fraction from the N2 transfection was only twice the level seen with wild-type ICP27 (cf. lanes 3 and 4); however, only about one-eighth as much nuclear RNA was recovered from this sample as determined by the actin control. In the cytoplasmic fraction, where recoveries were equivalent for all samples, there was four times as much $16 \mathrm{~S}$ and $19 \mathrm{~S}$ spliced product found in the N2 samples compared with the samples with wild-type ICP27, illustrating that this repressor mutant cannot down-regulate the accumulation of spliced RNAs.

\section{ICP27 activator mutants can inhibit ICP4- and ICPO-induced CAT expression}

Previously, we have reported the characterization of a series of in-frame insertion and deletion mutants within the ICP27 gene (Hardwicke et al. 1989). Mutations that mapped between amino acids 260 and 434 were termed activator mutants because they were defective in the ability to activate expression of pVP5-CAT, a derivative of the CAT-SYN A vector. Mutations within the carboxy-terminal $70-80$ amino acids were also defective in the ability to repress the expression of pTK-CAT and were termed repressor mutants, although they were defective in both functions. To determine whether these mutants would act in a manner similar to what was 
found with the CAT-SYN A- and pSV2-CAT-derived plasmids, an activator mutant and a repressor mutant were analyzed for their effects on the expression of target plasmids with different mRNA processing signals. The position of the activator mutant $\mathrm{S} 23$ and the repressor mutant $\mathrm{N} 2$ within the ICP27-coding region is shown in Figure 5.

Several of the target plasmids described in Figure 2 with different mRNA processing signals were used in transfections with either the wild-type ICP27 plasmid or with the activator or repressor mutants (Fig. 5). All of the target plasmids contained the TK promoter. The transfections were performed again with plasmids expressing the effectors ICP4 and ICPO to activate the low constitutive level of expression. The effect of wild-type ICP27 or the mutants was compared with the activated response. In accord with the data in Figure 2, wild-type ICP27 repressed CAT expression from target plasmids containing introns (Fig. 5, reporter constructs 2, 3, 5, and 7) and activated CAT expression from pTK-CAT-SYN A and pTK-CAT-HSV IE PA, which contains the ICP27 polyadenylation region (Fig. 5). The repressor mutant N2 did not repress CAT expression from any of the targets with introns, nor did this mutant activate expression of any of the plasmids above the level seen with ICP4 and ICP0. Therefore, N2 behaved in a manner consistent with the previously defined phenotype in that it was defective in the ability to repress and to activate. The activator mutant $\mathbf{S} 23$ repressed the activated expression of the target plasmids with introns as efficiently as the wild-type ICP27 plasmid, and S23 failed to activate expression of PTK-CAT-SYN A in accord with the phenotype of activator mutants. However, an unexpected result was found in transfections with plasmids pTKCAT-HSV IE PA, pTK-CAT-SV40 EPA, and pTK-CATSV40 LPA. S23 did not activate CAT expression above the ICP4- and ICPO-induced level, but the level of CAT expression was reduced 2.5- to 10-fold compared with the induced level. Target plasmids 2, 5, and 7 do not contain introns, and we had not observed previously any repressor effect by wild-type ICP27 on expression from targets without introns. Similar results were seen also with two other activator mutants, S13 and S1B /data not shown).

To investigate this observation further and to determine whether expression would be similar within the context of an HSV-1 infection, the experiments were repeated using wild-type and ICP27 mutant viruses. Transfections were performed with the same set of target plasmids, but no effector plasmids were added to the transfections. Instead, transfected cultures were infected with virus. Wild-type HSV-1 strain KOS infection provided ICP4, ICP0, and ICP27. The ICP27 null mutant 27-LacZ (Smith et al. 1992) is a viral insertion mutant in which the $\beta$-galactosidase gene was inserted in place of the ICP27-coding sequences. No ICP27 is expressed during infection of noncomplementing cells with 27-LacZ; therefore, this infection is equivalent to the condition of adding ICP4 and ICPO. Infections with the activator mutant S23 and the repressor mutant N2 were achieved by infecting cell lines expressing these mutants with $27-$ LacZ. The trans-dominant cell line Sst26, which expresses S23, and cell line Nsi37, which expresses N2, have been described previously (Smith et al. 1991). The results shown in Figure 5 were consistent with the results obtained with transfections using effector plasmids for all of the targets tested. Thus, infection with KOS that expresses wild-type ICP27 resulted in activation of CAT expression with pSV-CAT-SYN A and pSV-CATHSV IE PA, and repression of CAT expression for targets with introns (plasmids 3, 4, 5, and 6). Infections of cell line Nsi37 yielded results similar to those seen in transfections with N2, namely neither repression nor activation was observed as predicted for a repression region mutant. Infection of the S23-expressing cell line also resulted in effects on CAT expression similar to what was seen in transfections using S23 plasmid. That is, repression of expression was seen with intron-containing targets but also, as with the S23 plasmid transfections, the induced expression of target plasmids 2,5 , and 7 by ICP4 and ICPO (expressed in 27-LacZ infections) was also inhibited even though these targets do not contain introns. Therefore, the effects on CAT expression seen in the transfections using combinations of effector plasmids were not caused by nonspecific effects such as possible changes in the levels of the other activators by ICP27 or potential promoter competition as a result of cotransfecting a number of different plasmids. The same effects on expression were seen within the context of a viral infection. A possible explanation for the unexpected inhibitory action of S23 will be considered further below.

\section{Discussion}

Recent studies on the regulation of a number of cellular genes and on viral gene products have made it increasingly clear that post-transcriptional control mechanisms play a crucial role in modulating gene expression. In this study we have focused on the mode of action of ICP27, an essential regulatory protein of HSV-1, which is required for the switch from early to late gene expression during infection. By analyzing the effect of ICP27 on the expression of target genes during transfection experiments, it has been determined that ICP27 can act as a trans-activator or a trans-repressor of gene expression, depending on the target gene (Everett 1986; Block and Jordan 1988; Rice and Knipe 1988; Sekulovich et al. 1988; Hardwicke et al. 1989; Rice et al. 1989; McMahan and Schaffer 1990; Rice and Knipe 1990; Smith et al. 1991). During these studies we found that ICP27 affected the expression of two reporter genes differently, even though both contained identical promoter-regulatory regions. Two other human herpesvirus activator proteins have been reported to function in a reporter gene-dependent manner, specifically, BMLFl from Epstein-Barr virus (Buisson et al. 1989; Kenney et al. 1989), a homolog of ICP27, and the major trans-activator protein from human herpesvirus 6 (Campbell et al. 1991). However, the basis for the reporter gene response was not investigated in these studies. In this report we analyzed the differ- 
ences between the reporter genes and found that ICP27 activated or repressed expression of target plasmids in response to different mRNA processing signals.

The activation effect of ICP27 correlated with the presence of specific polyadenylation regions in the target genes (Figs. 3 and 4). McLauchlan et al. (1989) have reported that HSV-1 induces a processing factor that stimulates poly(A) site usage. In their studies, a late HSV-1 poly(A) site was processed more efficiently in nuclear extracts from HSV-1-infected cells compared with mockinfected cells, but another poly(A) site from an HSV-1 early gene was processed with equal efficiency. Although these investigators did not identify the factor, they provided evidence indicating that it was likely to be an immediate-early gene product. It is possible that ICP27 is this processing factor. In the target plasmid termed pSVCAT-SYN A, CAT poly $(A)^{+}$RNA was barely detectable unless ICP27 was present in the transfection (Fig. 3). The polyadenylation signal in this plasmid lacks a sequence resembling a G/U box positioned 20-30 nucleotides downstream of the AATAAA hexanucleotide /Gil and Proudfoot 1984; McDevitt et al. 1984; McLauchlan et al. 1985). A small stretch of Ts is found starting $\sim 42$ nucleotides farther downstream. It has been shown that poly $(A)$ site usage is decreased severely when the distance between the AATAAA signal and the G/U box is increased beyond 40 nucleotides /Gil and Proudfoot 1984; McDevitt et al. 1984; Brown et al. 1991). It is possible that ICP27 increases the amount of poly $(\mathrm{A})^{+} \mathrm{RNA}$ from this target by enhancing selection of this otherwise inefficient site. Poly $(A)^{+}$RNA of the size predicted by cleavage and poly $(\mathrm{A})$ addition occurring 10-30 nucleotides downstream of the hexanucleotide was seen in significant amounts only when ICP27 was present (Fig. $3 \mathrm{C})$. We have evidence that this downstream region must be present for increased expression by ICP27 because when the region 3 ' to the AATAAA sequence was deleted by treatment with Bal31, CAT expression could not be detected in the presence or absence of ICP27 (data not shown). In addition, in a related study, ICP27 was found to activate expression of a CAT vector containing MoMuLV regulatory sequences (Chapman et al. 1992). The stimulatory effect depended on the $3^{\prime}$-LTR sequences containing the polyadenylation region and was again promoter independent. This polyadenylation region has been reported to be inefficient when used in a luciferase expression vector compared with an SV40 poly(A) signal (Maxwell et al. 1991). These observations suggest that ICP27 somehow enhances polyadenylation efficiency from specific sites. These combined results suggest a role for ICP27 during polyadenylation.

A possible explanation for the inhibitory effect of the ICP27 activator mutant S23 on the induced expression of target plasmids without introns (Fig. 5) might be that the activation function occurs by direct participation of ICP27 in polyadenylation. It is possible that ICP27 interacts either with RNA or with processing factors to influence the efficiency of site selection. We have shown previously that activator mutants are trans-dominant and interfere with wild-type activity, whereas repressor mutants are not (Smith et al. 1991). Activator mutants, therefore, might still bind or interact with the polyadenylation complex but would be unable to perform the wild-type selection or stimulation function and thus could interfere with normal processing. Clearly, to define the mechanism, biochemical evidence is required to identify the molecules with which ICP27 interacts. These studies are currently under way.

The repressor activity of ICP27 was linked to the presence of introns in the target genes (Figs. 3 and 5). When the SV40 small t-antigen intron was present $3^{\prime}$ to the CAT-coding sequences or when SV40 16S/19S splice sites were present in the 5 -leader region of the CAT gene, significantly lower expression of CAT activity and decreased levels of CAT RNA were found. Although aberrant splicing patterns have been shown to occur with vectors containing the small $t$ intron $3^{\prime}$ to target-coding sequences (Huang and Gorman ${ }^{-} 990$ ), this is not likely to account for the effects observed with ICP27. In this study, expression of the vectors containing introns either $5^{\prime}$ or $3^{\prime}$ to the CAT gene was activated to high levels by the HSV- 1 activators ICP4 and ICP0, and decreased expression was found only when ICP 27 was present. Furthermore, correctly spliced products were found in the presence of ICP27 but in lower amounts (Fig. 4). The distribution of spliced products was similar in nuclear and cytoplasmic fractions, indicating that ICP27 exerted its effect on nuclear RNA. These results suggest that ICP27 may impair splicing. In this regard, HSV-1 infection results in the efficient shutoff of host protein synthesis. This is partly brought aboui by the action of the virion host shutoff function that facilitates the nonspecific degradation of host mRNAs and also viral RNAs (Read and Frenkel 1983; Oroskar and Read 1987; Strom and Frenkel 1987; Kwong et al. 1988). However, infections with ICP27 mutants are deficient in the shutoff of host protein synthesis (Sacks et al. 1985). One intriguing possibility to account for this observation is that ICP27 impairs splicing of host transcripts. HSV-1 is an unusual eukaryotic DNA virus in that the majority of its transcripts are not spliced (Wagner 1985). Those that are spliced are mostly immediate-early gene products that are made concomitantly with ICP27. In support of this hypothesis, Schroder et al. (1989) analyzed the change in processing of host cell transcripts in HSV-1-infected cells. They found that the processing efficiency of $\beta$-tubulin heterogenous nuclear RNA (hnRNA) was reduced by $2 \mathrm{hr}$ after infection and was inhibited almost completely by $5 \mathrm{hr}$, resulting in an accumulation of unspliced $\beta$-tubulin RNA. We have also found a decrease in spliced $\beta$-tubulin, actin, and GAPDH RNA after infection with wild-type HSV-1, but the level remained closer to that seen with mock-infected cells in ICP27 temperative-sensitive or null mutant infections (M.A. Hardwicke and R.M. Sandri-Goldin, in prep.). In addition, Martin et al. (1987) analyzed the distribution of host cell small nuclear ribonucleoprotein (snRNP) antigens after infection with HSV-1. A striking redistribution of snRNPs was seen. These investigators speculated that the formation of prominent snRNP clusters that condense in the nu- 
cleus and then move to the periphery as infection proceeds results from partial inactivation of host pre-mRNA splicing as a result of HSV-1 infection.

The data presented here suggest that ICP27 participates in mRNA processing. We have considered other post-transcriptional control steps, but these seem to be less likely, although at this point they cannot be rigorously excluded. That is, ICP27 does not appear to be involved in transport because the distribution of spliced CAT transcripts was similar in the nuclear and cytoplasmic fractions. Futhermore, in studies using a monoclonal antibody against the pore-complex lamina fraction from CV-1 cells, Schroder et al. (1989) did not find any changes in the nucleocytoplasmic transport system after infection with HSV-1. RNA stability could also be affected by ICP27. We have not measured RNA half-lives directly to test this possibility. However, many mRNAs that exhibit regulated turnover contain sequences that affect their stability or additional factors or specific proteins are required for stabilization (Atwater ct al. 1990). In the experiments described here, the mature CAT mRNA was the same in all cases, only sites that would affect pre-mRNA processing were different. Therefore, if ICP27 affected the stability of thesc CAT RNAs, it would have to have occurred before processing. On the basis of these considerations, it is more likely that ICP27 functions at the level of processing.

These findings are not only important from the point of view of gene regulation during viral infection but also because elucidating the nature of the interaction of ICP27 with components of the RNA processing machinery may help to uncover new information on polyadenylation and splicing reactions and how they might be linked.

\section{Materials and methods}

Recombinant plasmids, viruses, and cell lines

The effector plasmid pSG28K/B, which encodes the HSV-1 ICP4 gene; pRS-1, which encodes the ICPO gene; and $\mathrm{pSC}$ 130B/S, which encodes the ICP 27 gene have been described previously (Sekulovich et al. 1988). The construction of the ICP27 insertion mutant plasmids S23 and N2 has been described previously (Hardwicke et al. 1989), as has the characterization of the S23expressing cell line Sst26 and the N2-expressing cell line Nsi37 (Smith et al. 1991). The ICP27 viral insertion mutant termed 27-LacZ was described in Smith et al. (1992). pSV2-CAT was obtained from B. Howard (Gorman et al. 1982). pTK-CAT and pgB-CAT were derived from pSV2-CAT, as described previously (Sekulovich et al. 1988). The plasmid termed pVP5-CAT in Figure 1 is a derivative of pSV2-CAT. The promoter region from the HSV-1 VP5 gene from position -650 to -200 (Blair and Wagner 1986) was cloned into the HindIII site of pSV2-CAT after removal of the SV4O promoter sequences. The target plasmids designated as CAT-SYN A were derived from pSVOd/ori /-CAT (Costa et al. 1985) obtained from E.K. Wagner. The HSV-1 TK promoter from -510 to +55 (pTK-CATSYN A), the glycoprotein B promoter from -520 to +40 (pgBCAT-SYN A), the VP5 promoter from -650 to + 200 (pVP5CAT-SYN A), and the SV40 early promoter and enhancer sequences (pSV-CAT-SYN A) from pSV2-CAT were cloned into the HindIII site of pSVOd(ori ${ }^{-}$-CAT. The plasmid pTKCAT-SYN A was used for the cloning of the other plasmids shown in Figure 2, which contain different polyadenylation sites. Polyadenylation regions were cloned into the BamHI site that occurs $\sim 90$ bp downstream of the CAT translational stop codon. To obtain the plasmid termed pTK-CAT-SV40-EPA, a 133-bp HpaI-BamHI fragment, which contains the SV40 early poly $(A)$ site, was added. Similarly, a 196-bp fragment containing the SV40 late poly $(A)$ signal was obtained from the expression vector pTK $\beta$ (Clontech Laboratories) to construct the plasmid termed PTK-CAT-SV40 LPA. Two HSV-1 poly(A) sites were also used. The entire $3^{\prime}$-untranslated region was included in case there were sequences 5 ' to the poly(A) site that might be important. The poly $(\mathrm{A})$ region from the immediate-early gene was derived from the ICP27 gene itself. A 497-bp fragment from a S SpI site upstream of the ICP27 stop codon to a SstI site $\sim 300$ nucleotides past the poly $(A)$ site was purified from $\mathrm{pSG} 130 \mathrm{~B} / \mathrm{S}$. The CAT plasmid to which this fragment was added was termed FTK-CAT-HSV IE PA. The HSV-1 late poly $|\mathrm{A}|$ region was from the glycoprotein $C$ gene that has an unusually long 3 '-untranslated region Frink et al. 1983\}. An 856-bp MseI fragment originating 25 bp downstream of the translational stop and ending 15 bp downstream of the G/U box was used yielding the plasmid pTK-CAT-HSV LPA. The plasmid termed pTK-CAT-3'SSV40 EPA in Figure 3 was called pTK-CAT in our previous studies (Sckulovich et al. 1988; Hardwicke et al. 1989; Smith et al. 1991 and is also termed pTK-CAT in Table 1 and Figure 2. PTK-CAT-3'-HSV IE PA contains the polyadenylation site from the ICP27 gene in place of the SV40 early poly(A) region in pTK-CAT-3'S-SV40 EPA. The SV40 16S/19S late gene splice sites positioned $5^{\prime}$ to the CAT gene in pTK-CAT-5'S-SV40 EPA and pTK-CAT-5'S-SV40 LPA were obtained from pTK $\beta$ (Clontech Laboratories). A 180-bp fragment containing these sites was cloned into the BgIII and HindIII sites of pTK-CATSV40 EPA and pTK-CAT-SV40 LPA. pTK-LacZ was derived trom pONl (Spaete and Mocarski 1985). The HSV-1 TK promoter was inserted upstream of the lacZ gene in pON 1 .

\section{Cell culture and transfection}

Rabbit skin fibroblast (RSF) cells were grown as described previously (Sekulovich et al. 1988). For experiments in which CAT activity or $\beta$-galactosidase activity was measured, transfections were performed in $35-\mathrm{mm}$-diam. six-well cluster dishes as described previously (Sekulovich et al. 1988). Cells were harvested $48 \mathrm{hr}$ after transfection. CAT activity was measured by the diffusion assay of Neumann et al. (1987), modified as described previously (Sekulovich et al. 1988). $\beta$-Galactosidase activity was measured as described previously (Spaete and Mocarski 1985). In experiments in which viral infections were performed, RSF cells or the mutant-expressing Sst26 and Nsi37 cell lines (Smith et al. 1991) were transfected with the appropriate target plasmid. Sixteen hours later, cultures were infected with wildtype HSV-1 KOS or 27-LacZ (Smith et al. 1992). Cultures were harvested $12 \mathrm{hr}$ after infection. Transfection experiments in which RNA was isolated were performed in $100-\mathrm{mm}$ dishes as described by Sekulovich et al. (1988). RNA was harvested 24-36 hr after transfection.

\section{$R N A$ isolation and ribonuclease protection analysis}

Total RNA was extracted by the guanidium thiocyanate method $\left\{\right.$ Cathala et al. 1983). Poly $(A)^{+}$RNA was selected by using oligo(dT)-cellulose (Collaborative Research, Inc.) as described previously (Sandri-Goldin et al. 1983). Nuclear and cytoplasmic RNA fractions were isolated as follows. Cells were 
scraped into ice-cold PBS, centrifuged at $3000 \mathrm{~g}$, and resuspended in a lysis buffer consisting of $10 \mathrm{mM}$ Tris $(\mathrm{pH} 7.4), 3 \mathrm{mM} \mathrm{CaCl}_{2}$, $2 \mathrm{mM} \mathrm{MgCl}_{2}, 0.5 \%$ NP-40, and 500 units of RNasin (Promega). The cells were lysed by five strokes of a Dounce homogenizer. The nuclei were pelleted by centrifugation at $2000 \mathrm{~g}$ at $4^{\circ} \mathrm{C}$. The supernatant containing the cytoplasmic fraction was removed, and an equal volume of $6.5 \mathrm{M}$ guanidium thiocyanate was added to this fraction. The nuclei were washed gently in $1 \mathrm{ml}$ of lysis buffer to remove any remaining cytoplasmic material and pelleted again. The nuclei were then suspended in guanidium buffer $(3.7 \mathrm{M})$. Extractions with phenol-chloroform were performed as described previously (Sandri-Goldin et al. 1983). RNA samples were treated with RNase-frec DNase I (Promega) in the presence of RNasin for $60 \mathrm{~min}$ at $37^{\circ} \mathrm{C}$ to ensure that any residual plasmid DNA had been removed from the samples before the RNase protection assays were performed.

A T7 expression plasmid was cloned in which a fragment from pTK-CAT-5'S-SV40 EPA was inserted into pGEM-1 (Promega) to allow the in vitro transcription of a probe antisense to the 5 ' region of the CAT gene. The 490-bp insert was from an EcoRI site 240 bp downstream of the CAT translational start to the $B g I I I$ site in the $5^{\prime}$-untranslated region of the TK regulatory sequences. The SV40 16S/19S splice sites are within this fragment as shown in Figure 4. To transcribe the antisense probe, the plasmid was linearized with $\mathrm{Xbal}$ whose recognition sequence occurs in the pGEM-1 polylinker. The 3 ' antisense probe was derived from a T7 expression plasmid containing a 450-bp Ssp 1 fragment from pSV-CAT-SYN A encompassing $220 \mathrm{nu}-$ cleotides of CAT sequence, the polyadenylation site, and $200 \mathrm{bp}$ of vector sequences downstream of the AATAAA. This fragment was inserted into the SmaI site of pGEM-1, and orientation was confirmed by DNA sequencing. The plasmid was cleaved with IIindIII, whose recognition site occurs 30 bp downstream of the SmaI site in the polylinker. Antisense RNA was transcribed with $\mathrm{T} 7$ polymerase in the presence of $\left[{ }^{32} \mathrm{P}\right] \mathrm{CTP}$. Equal amounts of the RNA samples (usually $50 \mu \mathrm{g}$ ) were mixed with $5 \times 10^{5} \mathrm{cpm}$ of antisense RNA, which had been gel purified. Hybridizations and RNase protection assays were performed essentially as described by Zinn et al. (1983). The protected fragments were fractionated on $6 \%$ denaturing polyacrylamide-urea gels.

\section{Acknowledgments}

This work was supported by U.S. Public Health Service grant AI21515 from the National Institute of Allergy and Infectious Diseases to R.M.S.-G., who was also the recipient of U.S. Public Health Service research career development award AI00878.

The publication costs of this article were defrayed in part by payment of page charges. This article must therefore be hereby marked "advertisement" in accordance with 18 USC section 1734 solely to indicate this fact.

\section{References}

Ackerman, M., D.K. Braun, L. Pereira, and B. Roizman. 1984. Characterization of herpes simplex virus 1 alpha proteins 0 , 4, and 27 with monoclonal antibodies. J. Virol. 52: 108-118.

Adami, G. and J.R. Nevins. 1988. Splice site selection dominates over poly(A) site choice in RNA production from complex adenovirus transcription units. EMBO /. 7: 2107-2116.

Atwater, J.A., R. Wisdom, and I.M. Verma. 1990. Regulated mRNA stability. Annu. Rev. Genet. 24: 519-541.

Barrett, N.L., G.G. Carmichael, and Y. Luo. 1991. Splice site requirement for the efficient accumulation of polyoma virus late mRNAs. Nucleic Acids Res. 19: 3011-3017.

Berget, S.M., C. Moore, and P.A. Sharp. 1977. Spliced segments at the $5^{\prime}$ terminus of adenovirus 2 late mRNA. Proc. NatI. Acad. Sci. 74: 3171-3175.

Blair, E.D. and E.K. Wagner. 1986. A single regulatory region modulates both cis-activation and trans-activation of the herpes simplex virus VP5 promoter in transient expression assays in vivo. I. Virol. 60: 460-469.

Block, T. and R. Jordan. 1988. Herpes simplex virus type 1 alpha gene containing plasmids can inhibit expression regulated from an alpha promoter in CV-1 but not HeLa cells. Virus Res. 11: 269-279.

Brown, P.H., L.S. Tiley, and B.R. Cullen. 1991. Effect of RNA secondary structure on polyadenylation site selection. Genes \& Dev. 5: 1277-1284.

Buisson, M., E. Manet, M.C. Trescol-Biemont, H. Gruffat, B. Durand, and A. Sergeant. 1989. The Epstein-Barr virus (EBV) early protein EB2 is a posttranscriptional activator expressed under the control of EBV transcription factors EB1 and R. J. Virol. 63: 5276-5284

Bzik, D.J., B.A. Fox, N.A. DeLuca, and S. Person. 1984. Nucleotide scquence specifying the glycoprotein B gene of herpes simplex virus type 1. Virology 133: 301-314.

Campbell, M.E.M., S. McCorkindale, R.D. Everett, and D.E. Onions. 1991. Activation of gene expression by human herpesvirus 6 is reporter gene-dependent. J. Gen. Virol. 72: 11231130.

Cathala, G., J.F. Savouret, B. Mendez, B.L. West, M. Karin, J.A. Martial, and J.D. Baxter. 1983. A method for the isolation of intact, translationally active ribonucleic acid. DNA 2: 329335.

Chang, D.D. and P.A. Sharp. 1989. Regulation by HIV Rev depends upon recognition of splice sites. Cell 59: 789-795.

Chapman, C.J., J.D. Harris, M.A. Hardwicke, R.M. Sandri-Goldin, M.K.L. Collins, and D.S. Latchman. 1992. Promoter independent activation of heterologous gene expression by the herpes simplex virus immediate-early protein ICP27. Virology 186: 573-578.

Chow, L., R. Gelinas, T. Broker, and R. Roberts. 1977. An amazing sequence arrangement at the $5^{\prime}$ ends of adenovirus 2 messenger RNAs. Cell 1: 1-8.

Costa, R.H., K.G. Draper, G. Devi-Rao, R.L. Thompson, and E.K. Wagner. 1985. Virus-induced modification of the host cell is required for expression of the bacterial chloramphenicol acetyltransferase gene controlled by a late herpes simplex virus promoter (VP5). I. Virol. 56: 19-30.

Cullen, B.R. and W.C. Greene. 1989. Regulatory pathways governing HIV-1 regulation. Cell 58: 423-426.

DeMarchi, J.M. 1983. Post-transcriptional control of human cytomegalovirus gene expression. Virology 124: 390-402.

Emerman, M., R. Vazeux, and K. Peden. 1989. The rev gene product of the human immunodeficiency virus affects envelope-specific RNA localization. Cell 57: 1155-1165.

Everett, R.D. 1984. Trans activation of transcription by herpes virus products: Requirement for two HSV-1 immediate-early polypetides for maximum activity. EMBO J. 3: 3135-3141.

- 1986. The products of herpes simplex virus type 1 (HSV1) immediate early genes 1, 2, and 3 can activate HSV-1 gene expression in trans. J. Gen. Virol. 67: 2507-2513.

- 1987. A detailed mutational analysis of Vmw110, a trans-acting transcriptional activator encoded by herpes simplex virus type 1. EMBO I. 7: 2069-2076.

Everett, R.D. and M. Dunlop. 1984. Trans-activation of plasmid-borne promoters by adenovirus and several herpes group viruses. Nucleic Acids Res. 12: 5969-5978.

Felber, B.K., M. Hadzopoulou-Cladaras, C. Cladaras, T. Copel- 
and, and G.N. Pavlkis. 1989. rev protein of human immunodeficiency virus type 1 affects the stability and transport of the viral mRNA. Proc. Natl. Acad. Sci. 86: 1495-1499.

Frink, R.J., R. Eisenberg, G. Cohen, and E.K. Wagner. 1983. Detailed analysis of the portion of the herpes simplex virus type 1 genome encoding glycoprotein C. I. Virol. 45: 634-647.

Geballe, A.P. and E.S. Mocarski. 1988. Translational control of cytomegalovirus gene expression is mediated by upstream AUG codons. I. Virol. 62: 3334-3340.

Gelman, I.H. and S. Silverstein. 1986. Co-ordinate regulation of herpes simplex virus gene expression is mediated by the functional interaction of two immediate early gene products. /. Mol. Biol. 191: 395-409.

Gil, A. and N.J. Proudfoot. 1984. A sequence downstream of AAUAAA is required for rabbit beta-globin mRNA $3^{\prime}$ end formation. Nature 312: 473-475.

Goins, W.F. and M.F. Stinski. 1986. Expression of a human cytomegalovirus late gene is posttranscriptionally regulated by a 3 '-end-processing event occurring exclusively late atter infection. Mol. Cell. Biol. 6: 4202-4213.

Gorman, C.M., L.L. Moffat, and B.H. Howard. 1982. Recombinant genomes which express chloramphenicol acetyltransferase in mammalian cells. Mol. Cell. Biol. 2: 1044-1051.

Hardwicke, M.A., P.J. Vaughan, R.E. Sekulovich, R. O'Conner and R.M. Sandri-Goldin. 1989. The regions important for the activator and repressor functions of the HSV-l alpha protein ICP27 map to the C-terminal half of the molecule. I. Virol. 63: $4590-4602$.

Huang, M.T.F. and C.M. Gorman. 1990. The simian virus 40 small-t intron, present in many common expression vectors, leads to aberrant splicing. Mol. Cell. Biol. 10: 1805-1810.

Hyde-DeRuyscher, R. and G.G. Carmichael. 1988. Polyomavirus early-late switch is not regulated at the level of transcription initiation and is associated with changes in RNA processing. Proc. Natl. Acad. Sci. 85: 8993-8997.

Kennedy, I.M., J.K. Haddow, and J.B. Clements. 1991. A negative regulatory element in the human papillomavirus type 16 genome acts at the level of late mRNA stability. I. Virol. 65: 2093-2097.

Kenney, S., J. Kamine, E. Holley-Guthrie, E.C. Mar, J.C. Lin, D. Markovitz, and J. Pagano. 1989. The Epstein-Barr virus immediate-early gene product, BMLFl, acts in trans by a posttranscriptional mechanism which is reporter gene dependent. I. Virol. 63: 3870-3877.

Knipe, D.M. and J.L. Smith. 1986. A mutant herpesvirus protein leads to a block in nuclear localization of other viral proteins. Mol. Cell. Biol. 6: 2371-2381.

Kwong, A.D., J.A. Kruper, and N. Frenkel. 1988. Herpes simplex virus virion host shutoff function. /. Virol. 62: 912-921.

Leff, S.E., M.G. Rosenfeld, and R.M. Evans. 1986. Complex transcriptional units: Diversity in gene expression by alternative RNA processing. Annu. Rev. Biochem. 55: 1091-1118.

Leppard, K.N. and T. Shenk. 1989. The adenovirus ElB $55 \mathrm{kd}$ protein influences mRNA transport via an intranuclear effect on RNA metabolism. EMBO /. 8: 2329-2336.

Linney, E. and S. Donerly. 1983. DNA fragments from F9 PyEC mutants increase expression of heterologous genes in transfected F9 cells. Cell 35: 693-699.

Lucas, J.J. and H.S. Ginsberg. 1971. Synthesis of virus specific RNA in $\mathrm{KB}$ cells infected with type 2 adenovirus. I. Virol. 8: 203-212.

Malim, M.H., J. Hauber, S.-Y. Le, J.V. Maizel, and B.R. Cullen. 1989. The HIV-l rev trans-activator acts through a structured target sequence to activate nuclear export of unspliced viral mRNA. Nature 338: 254-257.

Martin, T.E., S.C. Barghusen, G.P. Leaser, and P.G. Spear. 1987.
Redistribution of nuclear ribonucleoprotein antigens during herpes simplex virus infection. J. Cell. Biol. 105: 2069-2082.

Maxwell, I.H., J.L. Brown, and F. Maxwell. 1991. Inefficiency of expression of luciferase reporter from transfected murine leukaemia proviral DNA may be partially overcome by providing a strong polyadenylation signal. I. Gen. Virol. 72: 1721-1724

McCarthy, A.M., L. McMahan, and P.A. Schaffer. 1989. Herpes simplex virus type 1 ICP27 deletion mutants exhibit altered patterns of transcription and are DNA deficient. I. Virol. 63: $18-27$

McDevitt, M.A., M.J. Imperiale, and J.R. Nevins. 1984. Requirement of a downstream sequence for generation of a poly $(\mathrm{A})$ addition site. Cell 37: 993-999.

McKnight, S.L., E.R. Gavis, R.C. Kingsbury, and R. Axel. 1981. Analysis of transcriptional regulatory signals of the HSV thymidine kinase upstream control region. Cell 25:385398.

McLauchlan, J.D., D. Gaffney, J.L. Whitton, and J.B. Clements. 1985. The consensus sequence YGTGTTYY located downstream from the AATAAA signal is required for efficient formation of mRNA 3' termini. Nucleic Acids Res. 13: $1347-1368$

McLauchlan, J., S. Simpson, and J.B. Clements. 1989. Herpes simplex virus induces a processing factor that stimulates poly(A) site usage. Cell 59: 1093-1105.

McMahan, L. and P.A. Schaffer. 1990. The repressing and enhancing functions of the herpes simplex virus regulatory protein ICP27 map to the C-terminal regions and are required to modulate viral gene expression very early in infection. I. Virol. 64: 3471-3485.

Neumann, J.R., C.A. Morency, and K.O. Russian. 1987. A novel rapid assay for chloramphenicol acetyltransferase gene expression. Biotechniques 5: 444-447.

Nevins, J.R. and M.C. Wilson. 1981. Regulation of adenovirus-2 gene expression at the level of transcriptional termination and RNA processing. Nature 290: 113-118.

O'Harc, P. and G.S. Hayward. 1985. Evidence for a direct role for both the 175,000 and 110,000 molecular weight immediateearly proteins of herpes simplex virus in the transactivation of delayed early promoters. J. Virol. 53: 751-760.

_ 1987. Comparison of upstream sequence requirements for positive and negative regulation of a herpes simplex virus immediate-early gene by three virus-encoded trans-acting factors. I. Virol. 61: 190-199.

Okayama, H. and P. Berg. 1983. A cDNA cloning vector that permits expression of cDNA inserts in mammalian cells. Mol. Cell. Biol. 3: 280-289.

Oroskar, A.A. and G.S. Read. 1987. A mutant of herpes simplex virus type 1 exhibits increased stability of immediate-early (alpha) mRNAs. I. Virol. 61: 604-606.

Perry, L.J., F.J. Rixon, R.D. Everett, M.C. Frame, and D.J. McGeoch. 1986. The IE 110 gene of herpes simplex virus type 1: Characterization by mRNA mapping, DNA sequence, oligopeptide antiserum and mutational analysis. I. Gen. Virol. 67: 2365-2374.

Proudfoot, N.J. and G.G. Brownlee. 1974. Sequence at the 3 ' end of globin mRNA shows homology with immunoglobulin light chain mRNA. Nature 252: 359-362.

Read, G.S. and N. Frenkel. 1983. Herpes simplex virus mutants defective in the virion-associated shut off of host polypeptide synthesis and exhibiting abnormal synthesis of alpha (immediate early) polypeptides. J. Virol. 46: 498-512.

Rice, S.A. and D.M. Knipe. 1988. Gene-specific transactivation by herpes simplex virus type 1 alpha protein ICP27. J. Virol. 62: 3814-3823. 
1990. Genetic cvidence for two distinct transactivation functions of the herpes simplex virus alpha protein ICP27. I. Virol. 64: 1704-1715.

Rice, S.A., L. Su, and D.M. Knipe. 1989. Herpes simplex virus alpha protein ICP2 7 possesses separable positive and negative regulatory activities. I. Virol. 63: 3399-3407.

Sacks, W.R., C.C. Greene, D.P. Ashman, and P.A. Schaffer. 1985. Herpes simplex virus type 1 ICP27 is an essential regulatory protein. J. Virol. 55: 796-805.

Sandri-Goldin, R.M., A.L. Goldin, L.E. Holland, J.C. Glorioso, and M. Levine. 1983. Expression of herpes simplex virus beta and gamma genes integrated in mammalian cells and their induction by an alpha gene product. Mol. Cell. Biol. 3: 20282044.

Schroder, H.C., D. Falke, K. Weise, M. Bachman, M. CarmoFonseca, T. Zaubitzer, and W.E.G. Muller. 1989. Change of processing and nucleocytoplasmic transport on mRNA in HSV-1 infected cells. Virus Res. 13: 61-78.

Sekulovich, R.E., K. Leary, and R.M. Sandri-Goldin. 1988. The herpes simplex virus type 1 alpha protein ICP27 can act as a trans-repressor or a trans-activator in combination with ICP4 and ICP0. J. Virol. 62: 4510-4522.

Shaw, A. and E.B. Ziff. 1980. Transcripts from the adenovirus major late promoter yield a single early family of $3^{\prime}$ coterminal mRNAs and five late families. Cell 22: 905-916.

Smith, I.L., R.E. Sekulovich, M.A. Hardwicke, and R.M. SandriGoldin. 1991. Mutations in the activation region of herpes simplex virus regulatory protein ICP27 can be trans dominant. J. Virol. 65: 3656-3666.

Smith, I.L., M.A. Hardwicke, and R.M. Sandri-Goldin. 1992. Evidence that the herpes simplex virus immediate early protein ICP27 acts post-transcriptionally during infection to regulate gene expression. Virology 186: 74-86.

Spaete, R.R. and E.S. Mocarski. 1985. Regulation of cytomegalovirus gene expression: Alpha and beta promoters are trans activated by viral functions in permissive human fibroblasts. I. Virol. 56: 135-143.

Stamminger, T., E. Puchtler, and B. Fleckenstein. 1991. Discordant expression of the immediate-early 1 and 2 gene regions of human cytomegalovirus at early times after infection involves posttranscriptional processing events. I. Virol. 65: 2273-2282.

Strom, T. and N. Frenkel. 1987. Effects of herpes simplex virus on mRNA stability. J. Virol. 61: 2198-2207.

Wagner, E.K. 1985. Individual HSV transcripts. In The herpesviruses, vol. 3 (ed. B. Roizman), pp. 45-104. Plenum Publishing, New York.

Wilcox, K.W., A. Kohn, E. Sklyanskaya, and B. Roizman. 1980. Herpes simplex virus phosphoproteins. I. Phosphate cycles on and off some viral polypeptides and can alter their affinity for DNA. J. Virol. 33: 167-182.

Zinn, K., D. DiMaio, and T. Maniatis. 1983. Identification of two distinct regulatory regions adjacent to the human $\beta$-interferon gene. Cell 34: 865-879. 


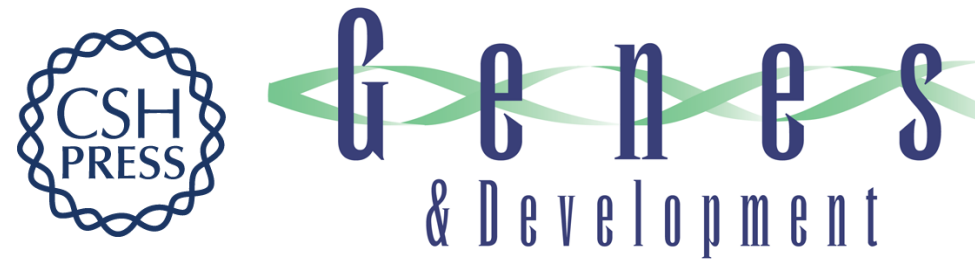

\section{A herpesvirus regulatory protein appears to act post-transcriptionally by affecting $\mathrm{mRNA}$ processing.}

R M Sandri-Goldin and G E Mendoza

Genes Dev. 1992, 6:

Access the most recent version at doi:10.1101/gad.6.5.848

References This article cites 74 articles, 38 of which can be accessed free at:

http://genesdev.cshlp.org/content/6/5/848.full.html\#ref-list-1

License

Email Alerting

Service

Receive free email alerts when new articles cite this article - sign up in the box at the top right corner of the article or click here.

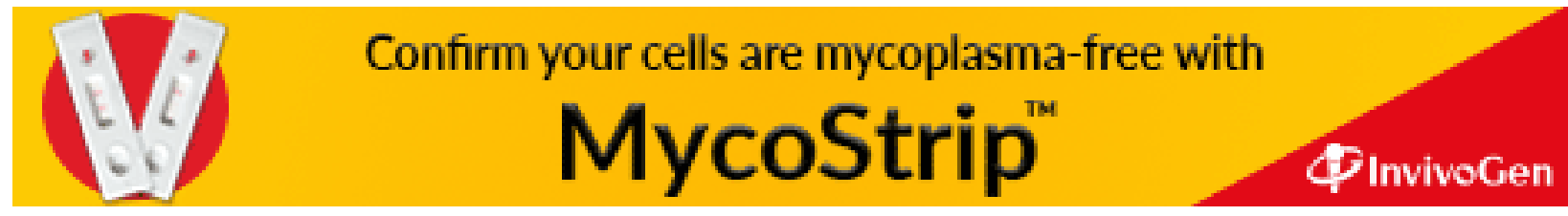

